This is the peer reviewed version of the following article: Cawston, A. (2016), Are Feminism and Competition Compatible?. Hypatia, 31: 204-220. doi: 10.1111/hypa.12222, which has been published in final form at http://dx.doi.org/10.1111/hypa.12222. This article may be used for non-commercial purposes in accordance With Wiley Terms and Conditions for selfarchiving. 


\section{Are Feminism and Competition Compatible?}

(earlier draft of paper accepted by Hypatia)

Amanda Cawston

Contemporary feminist interest in the persistent underrepresentation of women in top professions suggests an implicit approval of the competition required to achieve these posts. Competition, however, seems to be in tension with feminist opposition to domination and oppression. This paper outlines the dimensions of this tension and examines three attempts to resolve the incompatibility. The first two try to separate the undesirable elements of competition from the positive by way of the competitiveness/competition and the challenge/scarcity distinctions. I argue that these distinctions fail to alleviate worries about competition, particularly in the context of the professions. Meanwhile the third reconciliatory attempt offers a pragmatic argument for compatibilism based on the value of women's participation in the professions (and their associated competitions). While this pragmatic argument has some merit, I argue it significantly overestimates the amount of competition acceptable for feminist participation. The end result is that, within the context of the professions, competition remains fundamentally in tension with feminism.

Competition became a topic of interest in feminist philosophical literature in the 1980s and early 1990s, as many of the powerful and highly valued positions and professions once closed to women (for example, business, politics, academia, and law) began to open up. These high-powered and prestigious professions seemed to offer both the measure of, and the tools for, ending patriarchy; that is, female achievement in these fields would both itself represent success for feminism and give women the insider opportunity to reform the very institutions that enforce patriarchy. Yet success in these professions required competition, which didn't sit well with some feminists. ${ }^{1}$ Competition seemed antithetical to important feminist aims, including for example, the promotion of solidarity, the abolition of hierarchy and domination, and the rejection of particular masculine norms that promote and support oppression. But

\footnotetext{
${ }^{1}$ See for example, Yudkin 1984; Keller and Moglen 1987; Matsumoto 1987; Duchamp 1988.
} 
competition also promised to motivate exceptional performance and achievements, build self-worth, and of course, offered the means by which to advance the status of women (via the greater representation of women in prestigious positions). Women in academia (and other professions) were personally confronted with this tension as they pursued their own careers and strove to advance those of other women, and prompted explicit debate on the (in)compatibility of feminism and competition. The force of this tension has since faded though, and today's feminists have largely lost interest in the debate. There is good reason however, in my view, to revisit it. There has been significant amount of work recently in uncovering the mechanisms behind women's persistently low representation in prestigious and powerful professions, including in the upper ranks of academic philosophy. This includes revealing the workings of implicit bias and stereotype threat, and advancing feminist critiques of professional philosophical practice. ${ }^{2}$ Such academic interest exists alongside growing popular interest in women's professional success more generally, evidenced for example by the popularity of Sandberg's (2013) and other self-help style products for the aspirational career woman. Much of this work implicitly assumes the tension between feminism and professional competition has been resolved, suggesting that some form of compatibilism - that, in some sense, good feminists can compete in the professions - has become the received view. ${ }^{3}$ In so assuming, this otherwise important work both misses the opportunity for more fundamental critiques and risks validating or reinforcing structures and practices that are seriously at odds with feminism.

In this paper, I aim to rekindle interest in the tensions between feminism and competition. Specifically, I argue that despite several attempts to reconcile feminism and competition in the professions, tension stubbornly remains. After expanding on the key concepts of feminism and competition that produce the relevant tensions and frame the subsequent analysis, I then discuss three attempts to address these conflicts, two which try to separate the undesirable elements of competition from the positive by way of relevant distinctions, while the third amounts to a pragmatic argument based on the value of women's participation in the professions. All three, I argue, fail: the former pair's distinctions fail to alleviate worries about competition, particularly in the context of the professions, while the latter pragmatic argument, though possessing some merit, significantly overestimates the amount of competition

\footnotetext{
${ }^{2}$ See work by Beebee 1990; Haslanger 2008; Hutchison and Jenkins 2013.

${ }^{3}$ See e.g. Davion's 1987 paper, "Do Good Feminists Compete".
} 
acceptable for feminist participation. I end with some cautionary remarks regarding the pervasiveness of competition in contemporary life and the serious problem this poses for the possibility of genuine political change.

\section{'Feminism' and 'Competition'}

To begin, I should first clarify two essential terms of this paper, 'competition' and 'feminism'. Regarding the latter, I follow bell hooks' definition of feminism as: "a movement to end sexist oppression" $(1984,31)$, as well as her insistence that any such movement must recognize the distinct but intersecting modes of oppression that women of varying classes, races, ethnicities, sexualities, ages, and abilities experience. Feminism, then, is concerned with the mechanisms and structures of oppression and domination, understood broadly and as operating across multiple dimensions. As Bordo notes, this should not mean that every feminist theorist must attend to all dimensions of oppression at all times (such a demand is unfeasible and unhelpful), but rather, should endorse a pluralist view of feminism that is cognizant of its members' limited perspectives (1993, 220-229). hooks' definition allows for this pluralism, and can welcome the insights from different historical threads of this movement that have revealed various mechanisms of oppression, including for example, Marxist, Socialist, Radical, and Anti-racist feminisms. It is not all-encompassing however: as hooks is keen to point out, 'feminism' is not synonymous with 'anything goes' (1984, 23). Specifically, she rejects the pursuit of equal social status between men and women, an aim she attributes to Liberal (bourgeois) feminism and its focus on equal representation. As hooks explains, the pursuit of social equality reflects a simplistic understanding of oppression and privileges the perspectives and interests of middle and upper-class white women. It seeks to redistribute the benefits of oppression rather than dismantle its supportive mechanisms and attitudes.

With that said, it may seem that the conclusion of this paper is determined at the outset, for if feminism is defined in opposition to the aim of social equality, then it will naturally conflict with pursuing social equality in the professions via competition. As Woolf argues, the professions embody institutionalized power and privilege, and their value and prestige is fundamentally tied to exclusion, scarcity, and elitism. Achieving equal representation with men in such institutions may merely equally implicate women in the perpetuation of domination. 
Such a dismissal is too quick. Contemporary debates are motivated by a more nuanced version of the social equality aim: instead of equal representation being the end in itself, greater representation of women in prestigious and privileged positions is viewed as a means to achieving more fundamental change. The professions need not remain strongholds of privilege and domination, they can be made more open, more egalitarian, and less exclusionary with the help of feminist insights. Further, the reforms necessary for, and resulting from, greater female representation in the professions may contribute to greater, revolutionary social change. And while it is far from clear that the simple presence of more women in positions of power would be sufficient to effect change in support of feminist policies, it seems plausible to suggest that it is a necessary condition, allowing feminists to advocate participation in the professions strategically, as a way to change things from within. ${ }^{4}$ So, while the topic of competition in the professions shares its focus with the problematic Liberal aim of social equality, the call for greater female representation can be framed in terms of the more nuanced view, and cannot be rejected simply on the basis of our definition of feminism. The question of whether feminism (so construed) is compatible with competition in pursuit of professional positions remains open.

Regarding the other essential term, there are many activities that might easily fall under the term 'competition', including for example, a friendly game of tennis, a professional boxing match, a Miss America pageant, a court case, a philosophical debate, an election, and a war. And while there may be some common features amongst these activities that suggest a shared definition of competition, such a general description will likely be somewhat misleading and unfit for the purpose of this analysis which is to examine problematic connections between competition and sexist oppression. There are significant differences in the structure of advantage and the regulation of privilege associated with some competitions and not others - a difference that is lost when considering competition in the abstract. Running in a foot race is different than running for President of the USA, and an analysis that aims to encompass both will be ill-equipped to tell us about the role of competition in oppression and domination.

\footnotetext{
${ }^{4}$ This assumption has been criticized by Power (2009) who argues that simply having a woman in power does not necessitate that she will be sympathetic to women's issues. She names several examples, including Sarah Palin, Margaret Thatcher, and Condoleezza Rice as powerful women whose conduct served to undermine feminist aims.
} 
So, while recognizing the ideological function that competition likely has in many of the above activities, here I restrict my analysis to a certain spheres of activity where competition occurs. Specifically, to the sphere that Woolf (1938) refers to as "the professions". The professions, for Woolf, refer to regulated, prestigious, and privileged forms of employment, including the military, civil service, law, government, the church, and academia, as well as the various institutions of formal education required for their entry. ${ }^{5}$ Integral to these institutions are the entrenched values of rank and status, the significant advantages that accompany their positions, and their close connection with the social, political, and economic powers associated with contemporary modes of oppression. ${ }^{6}$

Even in this restricted sphere however, offering a definition of competition remains problematic. This is partly because the essential features of competition are precisely what is at issue in this debate, so it's impossible to give a definition that would not somewhat settle the matter in advance. But it is also because competition in the professions can refer to a variety of things that do not 'reduce' to a singular definition. It can, for example, mean a type of activity in which participants produce and submit work or abilities for comparative evaluation and recognition. It can also include a condition, or a state of competition, alluding to socialist feminist concerns regarding the capitalist production of scarcity and mechanisms that undermine cooperation. Finally, it can refer to an attitude or character: a way of interacting with others or perceiving others that is guided by a concern for acquiring or demonstrating superiority and power. All three forms of competition are present in the professions, often in integrated and mutually reinforcing ways, and together mark the subject of this analysis.

While there are numerous critiques one can make of competition, feminist concern has primarily been with the types of character traits deemed necessary for competitive success. These are the qualities and desires that drive one to beat one's opponent, to win the argument, to be the top of the class - in other words, to succeed

\footnotetext{
${ }^{5}$ In her analysis of barriers to women's advancement, Valian considers similar fields, including business, medicine, and law (including the judiciary) noting the shared general requirements of a college education and a professional degree, acquired via significant investments of "time, money, and energy" $(1999,187)$. She applies similar analyses to women in academia.

${ }^{6}$ This focus may appear at first glance to be worryingly elitist, that is, narrowly concerned with issues of interest only to already very privileged (white) women. It is, however, narrowly focused for the right reasons - it is precisely because of the connection between the professions and privilege that the professions are here under scrutiny.
} 
in the competitive professions. Such traits include, for example, aggression, ambition, self-interest, combativeness, assertiveness, forcefulness, and self-assuredness. From a feminist perspective, there are two problems with these traits. First, one may suspect that given their historical association with maleness ${ }^{7}$, in contrast to many of the traditionally 'female' qualities of selflessness, modesty, deference, and dependence, success for women essentially requires cultivation of masculine traits and avoidance of feminine, non-competitive traits. ${ }^{8}$ In other words, competitive success requires that women become more like men. And while there is disagreement on the extent to which female gender norms can and should be changed, most would be wary of a prescription for success that required such one-sided adoption of 'male' qualities.

The second problem concerns the nature of the competitive qualities themselves, outside of their gendered association. One predominant complaint is that these qualities and behaviors are historically and structurally linked to war and domination, and that valuing them, even in the context of the professions, contributes to and is constitutive of the glorification of war, hierarchy, and domination. Davion (1987), for example, attributes this complaint to Woolf (1938) and Yudkin (1982) in their criticisms of competition in the professions, and to Ruddick more generally. And there are clear similarities in the language and metaphors used to describe war and other competitive activities: Rooney, in her (2010) analysis of the adversarial method of argumentation in philosophy, discusses the 'argument-as-war' metaphor, noting the war-like language employed, including terms such as 'opponents, adopting or defending positions, scoring points, winning or losing arguments' (211). ${ }^{9}$ A related criticism places the virtues of competition in opposition to those of cooperation, nurturing, anti-hierarchical collectivity, and communal support, where the former ground problematic relations of domination and hierarchy and the latter are necessary to avoid and overcome such oppressive relations. ${ }^{10}$ Competing in the professions then, may promote the development of traits and behavioral norms that constitute domination and contribute to war, and therefore, conflict with the feminist rejection of domination. These initial problems with competition do not however, mark it as

\footnotetext{
${ }^{7}$ See Moulton $(1983,149)$.

${ }^{8}$ While not exhaustive or universal, (i.e. they do not capture the variability of normative conditions experienced by all women across race, class, or sexuality differences), it is fair to describe these traits as associated with 'the feminine'.

${ }^{9}$ See also Ayim 1991 and Cohen 1995.

${ }^{10}$ This type of criticism is characterized by Longino as the "radical and socialist rejection of competition" $(1987,256)$.
} 
immediately incompatible with feminism. As I go on to discuss, one strategy aimed at reconciling feminism and competition attempts to show that the worrisome attitudes and motivations currently associated with competition are only contingent features and can (and even should) be trimmed without rejecting competition itself. Whether these contrary elements of competition can in fact be trimmed is the key question of the next two sections of this paper.

In what follows, I consider two attempts to achieve this reconciliation. First, I examine compatibilist strategies to dissolve the tension by way of separating the valuable elements of competition from the undesirable ones via the introduction of two distinctions: the competitiveness/competition and the challenge/scarcity distinctions. I then consider the pragmatic argument that, while not strictly compatible, feminists must compromise their opposition to competition in light of the greater benefits of participation in the professions. I begin with a discussion of the first compatibilist proposal: distinguishing between competitiveness and competition.

\section{Competitiveness/Competition Distinction}

In her (1987) critique of Woolf and Yudkin, Davion argues that we can separate the problematic psychology of competitiveness from the activity of competition. She asks us to consider a friendly game of tennis, and notes that it is possible to play the game, that is, engage in the activity of competition, in a supportive and even cooperative manner. From this, she concludes that competitors need not exhibit the emotions of jealousy, greed and selfishness that Woolf and others link to war, but competitors can, and to some degree even need, to cooperate with each other in order to compete (in the sense that they need to be playing in accordance with roughly the same rules). And while it may be difficult for certain individuals to avoid feelings of competitiveness when competing, that the two are not necessarily linked provides space for reconciling feminism and competition.

Davion's specific aim is to show how competition differs from (or does not necessarily promote) war, though her distinction between competition and competitiveness has proved popular in wider discussions of competition and feminism. In particular, it makes an appearance in some feminist critiques of philosophical debate, often considered a competitive activity. Beebee for example, calls for a 
distinction between the 'style' and 'content' of debate or discussion: ${ }^{11}$ the hostile, combative, or aggressive style of a philosophical debate can be separated from the necessarily opposing or conflicting positions or points under discussion that form the content.

Distinguishing between competitiveness and competition resolves the incompatibility in two ways. First, by bracketing off the traditionally male emotions and behaviors of jealousy, greed, combativeness, aggression, and selfishness from the activity of competition, we avoid the complaint that competition requires women to become more like men. Second, the distinction allows compatibilists to avoid the worry that competition is a form of, or promotes, domination, as the behaviors and attitudes associated with domination are only contingently linked to competition. Furthermore, as Beebee suggests, we not only lose nothing by dispensing with competitiveness, we may in fact improve the practices that are currently characterized by it. We improve our chances, for example, of the 'truly' best philosophical argument 'winning' when we prohibit combative styles of argumentation that may draw support for a point for the wrong reasons. It looks, then, as if feminists may be able to rescue the potential benefits of competition while avoiding its problems, leading us towards a compatibilist position.

For all this, the distinction fails to completely dissolve the tension. For while we may be able to adjust our attitudes and behaviors during competition to avoid competitiveness, the negative emotions of competition, e.g., jealousy, greed, possessiveness, hostility, etc., do not just emerge during the activity of competition. Instead, as Woolf points out, they are more frequently the products of the outcome of competition. Specifically, such emotions spring from the earning of titles, degrees, letters, and ribbons, which are the ends of competition within the professions. Those who have 'won' become possessive of their prizes, greedy, fearful of others, and exclusionary. This is because these titles, letters, degrees, and other marks of 'merit' are not simple decorations, nor descriptions of skill level. Instead, they reflect facts of privilege and power. Woolf's evidence for this is empirical: she recalls, for example, the struggle female students at Cambridge had to acquire the right to place 'BA' after their names, a title associated with some prestige and privileges (particularly as regards employment advantages). In protest, male members of the university marched

\footnotetext{
${ }^{11}$ Beebee notes how this move parallels Govier's (1999) distinction between 'minimal adversariality' and 'ancillary adversariality'.
} 
on the streets of Cambridge, shaking angry fists, shouting and vandalizing the gates of the women's college. ${ }^{12}$ Woolf suggests other professions have evidence of similar possessive battles, and concludes:

...the professions have a certain undeniable effect upon the professors. They make the people who practise them possessive, jealous of any infringement of their rights, and highly combative if anyone dares dispute them." She asks, "[a]re we not right then in thinking that if we enter the same professions we shall acquire the same qualities? And do not such qualities lead to war? In another century or so if we practise the professions in the same way, shall we not be just as possessive, just as jealous, just as pugnacious, [...]as these gentlemen are now? $(1938,831)$

The upshot is that the problematic emotions tied to competition are not limited to those associated with the process of competing, namely competitiveness. The problem lies not only in how people behave as they compete but also in how they feel once they've won. If human beings then, are such that possessing power and privilege makes one possessive of that privilege, then the tension is not dissolved by requiring that such privilege and power is acquired in the right way (i.e. without competitiveness). Perhaps these feelings are less powerful or pernicious in Davion's friendly tennis match, since little is earned by 'winning', however, when competing in the professions, what we are competing for is power, and, as Woolf argues, when we acquire power, we become possessive and jealous of it, meaning that the problematic, war-like attitudes stubbornly reappear. ${ }^{13}$

One final point to motivate this objection is that the effort, sacrifice, and costs that competition in the professions demands helps to strengthen and legitimize these possessive, selfish and aggressive attitudes. Many individuals enjoying success today in the professions were not simply handed their titles, degrees, or letters (as in the past), but had to work hard, sacrifice much, and train for years to achieve their

\footnotetext{
${ }^{12}$ Woolf is referring to the protests following the vote in 1921 to continue to deny women full membership at the University of Cambridge. Male undergraduate students reportedly protested outside of Newnham College and damaged the bronze gates. See Women at Cambridge 1921.

${ }^{13}$ Rooney similarly objects to Govier's notion of minimal adversariality, arguing that it retains problematic features of the argument-as-war metaphor: "[s]uch metaphors established 'masculine' reason as embattled reason, as continually warding off the ever-lurking threats or distractions of 'feminine' unreason..." (2010, Introduction, 197). Importantly, the hostility that established 'masculine' reason directs towards 'feminine' unreason is not the product of insecurity during the process of competition, but from a position of privilege, and is motivated by a fear of losing its status and needing to protect its privilege.
} 
positions. Many spend significant amounts of their lives studying, training, saving for tuition fees, etc. as part of decade-long competition for success in the professions. ${ }^{14}$ In the face of such costs, the potential for aggression, possessiveness, and hostility towards those who might threaten to take or undermine one's privilege is clearly high.

In sum, the competitiveness/competition distinction fails to block the problematic attitudes of hostility, aggression, possessiveness, etc., and therefore fails as a route to reconcile feminism and competition. The remaining compatibilist strategy, and the subject of the following discussion, is the suggested distinction between 'challenge' and 'scarcity' models of competition.

\section{Challenge/Scarcity Distinction}

In her analysis of competition, Longino suggests that some competitions can work to motivate the participants, claiming that " $[\mathrm{t}]$ he more well matched they are, the more challenged and stimulated to run her best each entrant will be" $(1987,249)$. She is particularly keen to rescue these motivational benefits of 'competitive challenge' from what she regards as legitimate feminist concerns about competition's connection to domination and hierarchy. In her attempt to isolate these issues, Longino introduces a distinction between the challenge and the scarcity models of competition.

Longino's exemplar of a challenge-model competition is a footrace, where the outcome is determined by the differential abilities of the competitors; here, "[i]inequalities (differences, however momentary and transitory) in the relevant qualities of the competitors make for winners or losers" (1987, 249). Meanwhile, scarcity-model competitions are 'zero-sum' games where "limitations on the availability of the object sought make for winners and losers" (249), where this limitation is a product of the game's rules. Consequently, paradigmatic examples include baseball or tennis - games in which ties are structurally impossible, as competitors continue to play until there is a definite winner.

Using this distinction, Longino aims to clarify the grounds of disagreement between what she calls the radical feminist critique of competition, and the liberal feminist support for competition. To her mind, the liberal feminist support for

\footnotetext{
${ }^{14}$ Martin talks about the 'high cost of entry' to academia, though her concern is more about the costs to integrity, specifically how feminist scholars must alter their work in accordance with the established views to get published or hired (Martin 1999).
} 
competition overemphasizes the challenge-model of competition, unduly overlooking the problematic conditions of scarcity that work to regulate and protect positions of power and privilege. Conversely, radical feminists wrongly conceptualize all competition in terms of the scarcity-model, leading them to misunderstand all competition as a desire for domination, motivated via artificial conditions of scarcity necessary to maintain capitalism. The implication is that there may be room for competition within feminism, though it will depend on it being the right sort. For Longino, this space can be found by trying to disassociate the motivational benefits of competition from the negative scarcity-model. Presumably, we could avoid the legitimate feminist worries regarding artificial scarcity, hierarchy, and domination by participating only in genuine challenge-model competitions, thereby finding a route towards compatibilism. ${ }^{15}$

While the desire to be the best, or to out-do one's opponent, desires linked to the scarcity-model, may also be motivational for some, Longino implies that we need not aim to beat our opponents in order to want to do our best. While the scarcitymodel explicitly requires one to outdo one's competitors, the challenge-model merely lets this happen - it's not built into the model. Our desires therefore, need not necessarily be hierarchical or domineering, desires that conflict with feminism, rather we can simply rise to the challenge of the activity. ${ }^{16}$ Furthermore, while genuine hierarchies are explicitly enforced on the scarcity-model, any such ordering is accidental on the challenge-model. Thus challenge-model competitions appear to avoid the facts of domination and hierarchy, as well as the problematic desires for domination and the associated attitudes of aggression, possessiveness, and ambition that conflict with feminism.

One question however, is whether we can separate the motivational element in a challenge-style competition from the problematic desire to dominate or outdo one's competitors associated with the scarcity model. If we cannot, we have not resolved the tension. Additionally, if such a separation is possible, then it may be too

\footnotetext{
${ }^{15}$ Longino does suggest that in some contexts challenge-model competitions can be "damaging and divisive" (1987, 257), though this is at best a speculative and undeveloped point in her paper, and does not imply that all challenge-model competitions are problematic.

${ }^{16}$ Further support for attributing this view to Longino can be drawn from her analysis of the failure of socialist/radical feminist groups to deal with the challenges of internal leadership. She attributes the failure to the misunderstanding of any assertiveness within the group as a desire for domination in the style of scarcity-model competitions for power. The implication again is that this desire for domination is tied to scarcity and not challenge model competitions.
} 
successful, allowing the motivation to do one's best to be separated entirely from the challenge model as well, leaving no connection to the process of competition, and hence no motivation for compatibilism.

We can quickly note that we can separate the positive motivational element from competition, since performing a non-competitive activity with other people who are comparatively skilled or talented can motivate one to do one's best (though it need not necessarily do so). For example, I could join a group dancing lesson where my fellow dance students and I can be motivated by performing together, without this being a competition, since, according to Longino, "competition always involves a contest among individuals seeking the same thing when not all can obtain it" (250), and my dancing lessons lack this dimension. Competition does not seem necessary then, to motivate one to do one's best, undermining our reasons for pursuing a reconciliation project. However, we may pursue the current question regardless; if we can participate in challenge-model competitions and benefit from the positive motivational element (without the negative features of scarcity), then we can perhaps identify a kind of competition safe for feminists to pursue and even advocate. We must ask then, how might a challenge-model competition motivate a participant to do her best, and how might it do this in a way that differs from the non-competitive dance class from above, as well as from the dominating desires to outdo others associated with the scarcity model? Given Longino's understanding of what competition involves, what is it that the challenge-model competitors seek that all cannot obtain, where the reason they cannot all obtain it is not a condition of enforced scarcity?

Consider the simple footrace example that Longino uses to illustrate the challenge model. One possibility is that all participants are seeking to run their own personal best, this however does not satisfy our criteria, as all could (potentially) succeed in achieving this aim. A second possibility is that they are all seeking to run the 'fastest', whether or not this distinction comes with other material perks or rewards. This however, also falls foul of our criteria, as scarcity is built into the meaning of the label 'fastest'. To be the fastest is to have out-run, i.e. out-done, one's competitors, and we cannot escape the dominating nature of this label by redescribing the motivation. Perhaps this is a failure of imagination on my part, but I see little difference between wanting to win so that others lose, and wanting to win in a way that entails that others lose. 
A further possibility is that participants all seek to run the 'fastest', where 'fastest' is a label that can be shared. As Longino stresses when making the challenge/scarcity distinction, the virtue of the challenge model is that it doesn't enforce the result of single winners - in principle, all runners could cross the finish line at the same time. However, if it was genuinely possible for all, or even only most, of the runners to do equally well, then 'fastest' loses its meaning and we again lose any understanding of how this could provide motivation. If it is not genuinely possible, perhaps because of the natural differences in our abilities, then we are again faced with a situation in which competitors are all seeking a title that has value in virtue of its scarcity, though this scarcity is not built explicitly into the structure of the competition (as in scarcity model), but is only a consequence of our differences and the competition's ability to differentiate us accordingly.

My sense here is that Longino's challenge model merely shifts the problems with the scarcity-model, rather than resolving them. In challenge-model competitions, the scarcity is no longer explicitly enforced, but rather the result of differences between people. However, this offloading fails to avoid the domination concerns linked with the scarcity model. While the competitors need not have the direct desire to outdo or beat one another, they must instead aim to be the fastest, the brightest, the best, where this implies having outdone others. We may have avoided the obvious connection with domination by making this move - our competitors no longer need to actively desire to literally dominate the others - however, the facts of hierarchy, domination, and the emphasizing of superiority over others, remain. If we consider how such competitions work in the professions, titles, awards, and labels of achievement are valuable in virtue of the power, the very real advantages they confer. The emphasis being on advantage - these are titles, awards, etc. that are valuable because (relatively) few others have them. Not only does this look a lot like domination to me, it returns us to the concerns raised regarding the link discussed in the previous section between attaining privilege and feelings of greed, selfishness, possessiveness, and aggression.

I fail to see how challenge-style competitions can provide unique reasons for motivation that are relevantly different from motivation on the scarcity model. Without the titles, distinctions, and labels (and in the case of the professions, the power and privilege that come along with them), challenge-style competitions cease 
to be competitions, and become ordinary activities. With these titles, they cannot escape the charge of domination.

The emphasis in this and the preceding section was on the connection between competition, including the winning of titles, degrees, power, and privilege, and attitudes of possessiveness, selfishness, and ultimately, of domination. Admittedly, there is no necessary relation between winning a competition and these problematic qualities. It is possible for an individual to be motivated to achieve her own personal goals and to remain a 'humble' winner - to refrain from emphasizing superiority and exercising her acquired privilege. ${ }^{17}$ However, notice that to avoid the problems outlined above, the individual must not think of the competition as a competition, but rather as an ordinary, i.e. non-comparative activity. She cannot think of herself or her abilities as better than her competitors', nor that she is deserving of the awarded privilege. She must, in effect, refrain from competing. So, rather than offering a case where feminism and competition are compatible, the 'humble winner' is instead someone who engaged in an activity alongside others in competition, but did not herself compete. Such conduct is possible, though does not immediately dissolve all of our worries concerning competition and privilege. There remain problems, for example, with the legitimating power of participating in competition (even if one is not really competing), as well as the difficulty in pulling apart having and exercising privilege. However, the key question in such cases is, if the results truly mean nothing, why enter the competition? One answer, considered in the following section, is that feminists cannot afford not to.

\section{Competition as a 'Necessary Evil'}

A third, pragmatic route to address the tension, hinted at by Longino, Martin, Beebee, and others, is to argue that the benefits of participating in the professions sufficiently outweigh any concerns regarding participation in their competitions. We may not be able to rid competition of its inherent tension with feminism, but the benefits of participating in the professions are too great to ignore - or conversely, the costs of not participating are too high. Adopting a (pseudo)compatibilist view is more of an offer that feminists cannot refuse than a happy reconciliation.

\footnotetext{
${ }^{17}$ Thank you to an anonymous reviewer for raising this issue.
} 
There are two ways to conceive of this approach. One is to view women's professional success itself as the valued end, part of an overarching and nonforfeitable aim of achieving equal representation in prestigious and powerful positions. This conception however, cannot legitimate (even) a pseudo-compatibilism, given its conflict with the definition of feminism advanced at the start, and can therefore be put to one side. Another way to conceive of this approach that does not run afoul of our definition of feminism, is to view professional success as a means to a valuable end, that is, as a means to ending sexist oppression. The power and influence that comes with professional success provides the means, it is thought, to effect change. This might be to change policy relating to issues external to the profession, or it could be to change the profession itself. This approach, in academic philosophy, is reflected in the call for greater numbers of female professors, which, it is thought, will be both the impetus for and consequence of, eliminating sexist oppression from the profession. Moreover, reforming academia will have beneficial, knock-on effects for feminism more generally, as the disempowered gain a voice and the dominant class loses its grip on the production of knowledge. In short, to those who worry about the connection between the professions and privilege and oppression, proponents of this view "can retort that by entering the public world they will change it" (Longino 1987, 255). While this view more astutely reflects the motivations underlying recent calls to increase female representation, there are three substantial issues to raise that undermine, or at least significantly limit, its potential to justify competition in the professions. All three point to the effects competition has on undermining or restricting the potential for change, either within the professions or in the general political sphere.

The first problem is the difficulty in changing the professions while in the process of competing for a position. Here, sporting analogies may be useful. It is clear that if you want to play professional tennis, you have to play by the rules. The rules govern what counts as a point, what counts as a foul or penalty, and what can get you thrown out of the game. Norms of practice govern (though less formally) the kinds of movements you should make, the tools you might use, your training regime, etc. There is little, if any, room for novel styles of play. The top professional tennis players have acquired their status as a consequence of following highly restrictive and precise norms of 'good play'. Similarly, competition in the professions works in the same way, to motivate (or discipline) acting in specific ways in accordance with 
accepted norms. ${ }^{18}$ Of course, the rules and norms of behavior in the professions are not as formalized as professional tennis, though it would be false to say there are no such rules or norms (or that they aren't formalized at all). Furthermore, these rules and norms are defined in ways that protect the established institutions and professions rather than allow much in the way of challenge.

Dotson, for example, expresses frustration with how norms governing what counts as 'philosophy' work to restrict avenues of inquiry, privileging debates and questions that are already established, and consequently prevent transformation of the profession. In her experience, alternative conceptions that diverge from the dominant view of philosophy 'as critique', are not welcomed as innovative styles of play, but are challenged. She is frequently asked but "[h]ow is your project philosophy?" (2011, 406) to which in response, she finds herself modifying and repackaging her work such that can 'pass' according to prevailing norms. ${ }^{19}$ But such 'passing' leaves the dominant norms intact. It is clearly difficult then, if not impossible, to undermine or subvert the norms while you participate in them, which you need to do in order to compete. Feminists must pin their hopes then on being able to effect change after having achieved a position, for it is very difficult, if not impossible, to change them in the process of competition.

The second problem relates to the effects of competition on the successful competitors, effects that hamper their subsequent ability to change the professions. There are two such effects to discuss. First is the selecting and transforming function of the competition itself. In her analysis of the assimilation of women into the academy, Martin notes that academia has so far been very successful in co-opting and restricting feminist scholarship, incorporating women in a uni-directional pattern of change, suggesting we lose our anti-establishment aims and ideas as we join and are selected by, the establishment. She suggests further that the process of assimilating, that is, learning to write in the accepted language, to think about the acceptable topics, etc. is not a superficial act, but a somewhat irreversible change in the assimilated, leaving the newly minted academic without the valuable, outsider perspective that offered the tools for change. Berruz recounts her own experience, as a Latina in philosophy, of the pressure to assimilate, but also of what she calls the 'wounding'

\footnotetext{
${ }^{18}$ For a related discussion of the disciplining effects of professional philosophy, see Jenkins 2013.

${ }^{19}$ Berruz offers a similar description of the need to abide by philosophy's prescriptive norms, which she also describes as 'passing' $(2014,184)$.
} 
effects of 'duplicity' - a protective strategy to resist assimilation via a shift between two selves. She warns that "[d]uplicity assumes a return or shift back to a genuine self that existed before the duplicitous act, but the truth remains that there is no original self to return to" $(2014,183)$. As many have already testified, the assimilationist force of trying to 'pass', i.e. to compete, in the professions is very real, and its stifling effect on revolutionary potential needs to be taken seriously.

The second effect is the role of competition in giving the 'winner' a reason for perpetuating the exclusionary practices of the professions. In his discussion of competition and co-operation (from the economic perspective), Coleman notes that co-operation is in fact the better strategy for the capitalist than competition. A group of producers can co-operate to fix prices so that the maximum can be extracted from the consumer. Furthermore, one way to protect a co-operation scheme is to require a large entry fee into the club, thus ensuring that new entrants have a stake in perpetuating the scheme. This rings familiar, particularly when we remember that academia, the church, politics, etc. were once described as 'old boys clubs', 'brotherhoods' - they are in fact better characterized by co-operation rather than competition, at least once you're in. The high entry fee though also rings familiar, as well as Coleman's description of how it functions to ensure new entrants have a stake in enforcing the exclusivity (else her 'investment' is lost). It is precisely the high cost of competing to acquire positions in the professions that helps to undermine one's desire to make them more open and less privileged.

This of course doesn't mean it is impossible for an individual who has paid that dear entry fee to then reject the advantages of 'brotherhood', only that it is unlikely and quite difficult. Just how difficult, is in my view, vastly underestimated and misunderstood by many feminists.

The third problem is the impact that competition has on undermining the potential for the professions to effect wider political change. This is a similar though more complex issue to that discussed as part of the first problem, and to help detail the concern, I turn again to Woolf's rich critique of the professions. Central to Woolf's view is the firm belief that political change requires truth, by which she means individuals having the time, resources, and the freedom (from fear) to say, write, and create what they think, want, and will. Without this freedom, whatever is said, written, or created cannot be new, but must say what it is told to say, write what it is directed to write, and create what it is expected to create. Woolf recognized that 
entry into the professions represented a path to some of this necessary freedom for women, ending their total financial dependence on men and providing the means to 'earn enough to live on'. She is keenly aware however, of the ways in which our participation can constrict this all important freedom and honesty and again become a resource for the dominant view. She describes what she calls the 'adulterating' motives of money, vanity, advertisement, and publicity, the spoils of competition in the professions, where work that results from these motives is necessarily biased, and at best not 'the whole truth', having been influenced by the dominant powers.

For example, Woolf cites the common practice in her time of reading three daily newspapers - three are needed in order to compensate for the biases each paper reflects. Journalists are either explicitly or implicitly required to produce articles that accord with the views of the owners and editors - they lack the complete freedom to write as they wish when writing for their editor as part of their job. In a similar vein, I am sure many aspiring and practicing academics are familiar with the task of writing a research proposal, or an article for publication, and how writing with these aims in mind changes how we write and what we say. In writing for example, with the 'publication-motive', or the 'funding-motive' in mind, we adulterate our work, undermining its potential to function as an expression of our genuine beliefs and opinions. Without the space to write about what we want to write about, and in our own words, we lose the opportunity to express a different view, to contribute to an actual change in society rather than more of the same. Our entrance into the professions can only be understood as progress if they provide the means for that all important freedom. Without this, the professions fail to function as a means to change.

Again, Woolf recognizes the opportunity for freedom that the professions provide, but to avoid having all of one's work within them suffer from adulteration, she advises us that once we have made enough to live on, we must stop practicing (i.e. use our free time for whatever else we like), or continue practicing but not for money, publicity or reputation, only the love of the work, allowing it to function as an genuine expression of ourselves. This may sound simple, but could be a tall order. In academia, for example, this might mean refusing a promotion to Professor, when you are well provided for at a Lecturer salary. Or, if one has achieved a post and no longer needs to demonstrate a record of published work, one proceeds to publish anonymously, or refuses to be highlighted as the 'keynote speaker'. These are difficult requests, and it is fair to ask if they need be this hard. However, I fear it is both too 
easy to give oneself the benefit of the doubt when evaluating one's own motives, and hard not to question the motives of others when considering their work. For there is also the worry that others can doubt the sincerity of your words and deeds when they are found within a context of competition or other adulterating motives, further undermining their potential for change.

The pragmatic argument then, that women should accept the potential ills of competition given the benefits of participating in the professions, at least partially fails. The more nuanced feminist aim of achieving change via participation is rendered problematic. Participation in the professions' competitions works to minimize, co-opt, and even negate the potential for genuine change. We cannot change things from within the competition, so we must, as much as possible, remain outside that game. ${ }^{20}$ So, while we find we must participate in the professions and their associated competitions to some degree, we must aim to limit our competition to the absolute minimum, a minimum that conflicts with contemporary calls for women to acquire greater positions of power and privilege.

\section{Competition in the 'Game of Life'}

This leads me to my final point, which is to suggest that our modern situation should give us particular cause for concern. In her One Dimensional Woman, Power offers an analysis of modern work, and challenges the claim that employment has proven emancipatory for women. In particular, she notes the increased precariousness of work, and the associated need to market more of your self to employers. Employers now look not only at professional skills and qualifications, but the character traits of professionalism. This includes evaluating volunteer work, athletics, drama, and committee work. These activities are then pursued for the purpose of building one's $\mathrm{CV}$ and are experienced as networking or professional development opportunities. Consider the following advice taken from the Cambridge Careers Guide pamphlet aimed at helping students with job seeking:

At Cambridge, it's easy to get involved in more of what you enjoy - from sports, music, committees to volunteering - and employers value this too ... Taking a

\footnotetext{
${ }^{20}$ Woolf (1938) writes of the value of women's outsider perspective, even proposing a Society of Outsiders as women's only possible avenue for political change.
} 
position of responsibility in a club, society or committee can be a great way to demonstrate teamwork, leadership, people skills, commercial awareness... $(2014,8)$

This development should give cause for serious concern. As I argued in the previous section, it was only actions performed outside of the professions and their competitions that had the potential for revolutionary effect. If the activities that were once ignored by the professions thereby providing that space, the room for selfdevelopment and expression, are no longer outside the scope of the corrupting motives of the professions, we have clearly lost ground rather than gained. I would end with a speculative and perhaps alarmist comment that this demand to make ever more of our selves subjects of the market is perhaps the one of most worrying issues facing feminists today. Rather than focusing on the persistent underrepresentation of women in top positions within the professions, or on how little we have gained, we should perhaps be alarmed at what we are losing, and at what the ever increasing reach of competition means for our potential to effect change.

To clarify, I am not suggesting that women should abandon the professions and refrain from pursuing satisfying careers. As Woolf resignedly observes, women must earn enough to live on, and the professions do offer a potentially fulfilling means for achieving this. I have argued however, following Woolf, that this leaves women between a rock and a hard place. Existing attempts to excise the negative elements of competition in the professions amount to superficial and ineffective reforms. Furthermore, the hope that participation in the professions' competitions would enable those participants to advance feminist aims has been similarly undermined. We are left squarely facing that stubborn rock and unyielding hard place. That said, I do not want to characterize our options as all-or-nothing choices, i.e. either we give up on the professions or we devote ourselves to acquiring as much privilege and power as possible. For many of us, some degree of participation is simply the only way open to us. There is a difference however, between resigning ourselves to participation and considering the tension therefore reconciled, and advocating a 'middle-way' (i.e. limited participation) that recognizes the unresolvability of the situation and demands that we continually re-evaluate just how much participation is necessary. Importantly, this re-evaluation should happen at the personal level - there is not a one-size-fits-all degree of participation that can be universally prescribed. Everyone's situation is different, and it is not for me, or 
anyone else, to condone or condemn an individual's professional success. In particular, I do not mean to imply that those without titles, degrees, or professorships should criticize those who have them (nor, for that matter, the other way around). Moreover, I would stress that identifying the concrete ways in which we can practice the professions outside their competitions, and thereby avoid hegemonic appropriation, is no easy task. Again, I am keen to avoid general prescriptions, especially given that individuals' motives for the same act can differ. But I also do not mean to leave each of us on our own - we certainly can, and should, think about this problem together and learn from others' reflections, experiments and experiences.

The demand however, is to take seriously the intractable dilemma that each of us faces, and for each of us to decide the direction we will take. It is also, to think more carefully about calls to see more women in high-ranking positions. In particular, we must consider how focusing on this aim diverts our attention and our resources from creating alternative spaces in which unadulterated work can exist. We must accept, though, that we cannot escape our rock and hard-place without some bruising. In my view, it is our desires for prestige, power, privilege, and domination that should take the bruising, which requires sacrificing certain levels of success, wealth, and recognition. But, as I have tried to show, for those who claim to reject privilege and domination, such sacrifices are no great loss, as they, in fact, mark the way to liberation.

\section{REFERENCES}

Ayim, Maryann. 1991. Dominance and affiliation: Paradigms in conflict. Informal Logic 13 (2): 79-88.

Beebee, Helen. 2013. Women and deviance in philosophy. In Women in Philosophy: What needs to change? Eds. Katrina Hutchison and Fiona Jenkins. New York: Oxford University Press.

Berruz, Stephanie Rivera. 2014. Inhabiting Philosophical Space: Reflections from the Reasonably Suspicious. Hypatia, 29 (1): 182-188.

Bordo, Susan. 1993. Unbearable Weight: feminism, Western culture, and the body. Berkeley; London: University of California Press. 
The 2014 Cambridge Careers Guide. 2014. Cambridge: The University of Cambridge http://viewer.zmags.com/publication/b9c193f8\#/b9c193f8/1(accessed November 20, 2014).

Cohen, Daniel. 1995. Argument is war...and war is hell: Philosophy, education, and metaphors for argumentation. Informal Logic 17 (2): 177-188.

Coleman, Jules. 1987. Competition and cooperation. Ethics 98 (1):76-90.

Davion, Victoria. 1987. Do Good Feminists Compete. Hypatia, 2 (2): 55-63.

Dotson, Kristie. 2011. Concrete Flowers: Contemplating the Profession of Philosophy. Hypatia, 26 (2): 403-409.

Govier, Trudy. 1999. The philosophy of argument. Newport News, Virginia: Vale Press.

Haslanger, Sally. 2008. Changing the ideology and culture of philosophy: Not by reason (alone). Hypatia 23 (2): 210-223.

hooks, bell. 1984. Feminist theory from margin to center. Boston: South End Press. Hutchison, Katrina and Fiona Jenkins (eds.). 2013. Women in philosophy: What needs to change? New York: Oxford University Press.

Jenkins, Fiona. 2013. Singing the post-discrimination blues: Notes for a critique of academic meritocracy. In Women in philosophy: What needs to change? Eds. Katrina Hutchison and Fiona Jenkins, New York: Oxford University Press.

Keller, Evelyn Fox and Helene Moglen. 1987. Competition and feminism: conflicts for academic women. Signs 12 (3): 493-511.

Longino, Helen. 1987. The ideology of competition. In Competition: A feminist taboo? Eds. Valerie Miner and Helen Longino. New York: The Feminist Press at the City University of New York.

Martin, Jane R. 1999. Coming of age in academe: Rekindling women's hopes and reforming the academy. London: Routledge.

Matsumoto, Debra. 1987. One young woman in publishing. In Competition: A Feminist Taboo? Eds. Valerie Miner and Helen Longino. New York: The Feminist Press at the City University of New York.

Moulton, Janice. 1983(2004). A paradigm of philosophy: The adversary method. In Discovering Reality. Eds. Sandra Harding and Merrill Hintikka. London: Kluwer Academic Publishers.

Power, Nina. 2009. One-dimensional woman. Hants, UK: O Books.

Rooney, Phyllis. 2010. Philosophy, adversarial argumentation, and embattled 
reason. Informal Logic, 30 (3): 203-234.

Rooney, Phyllis and Catherine Hundleby. 2010. Introduction: reasoning for change. Informal Logic 30 (3): 194-202.

Sandberg, Sheryl. 2013. Lean in: Women, work, and the will to lead. London: WH Allen.

Saul, Jennifer. 2013. Implicit bias, stereotype threat, and women in philosophy. In Women in Philosophy: What needs to change? Eds. Katrina Hutchison and Fiona Jenkins New York: Oxford University Press.

Valian, Virginia. 1999. Why so slow?: the advancement of women. Cambridge: The MIT Press.

Women at Cambridge. The Spectator, October 29, 1921 (4879): 551-552.

http://archive.spectator.co.uk/article/29th-october-1921/7/women-atcambridge (accessed March 16, 2015)

Woolf, Virginia. 1938 (2005) Three guineas. In Selected Works of Virginia Woolf. Hertfordshire: Wordsworth Editions.

Yudkin, Marcia. 1982. Reflections on Woolf's Three Guineas. Women's Studies International Forum. 5 (3/4): 263-269. 